\title{
The Solubility of Two Magnetite Powders in Oxalic Acid: Applicability of Empirical Modelling
}

\author{
Riina Salmimies, Mikko Huhtanen, Juha Kallas, and Antti Häkkinen \\ Department of Chemistry, Lappeenranta University of Technology, Skinnarilankatu 34, 53850 Lappeenranta, Finland \\ Correspondence should be addressed to Riina Salmimies; riina.salmimies@lut.fi
}

Received 26 September 2012; Revised 5 December 2012; Accepted 10 December 2012

Academic Editor: Tomasz Sosnowski

Copyright (c) 2013 Riina Salmimies et al. This is an open access article distributed under the Creative Commons Attribution License, which permits unrestricted use, distribution, and reproduction in any medium, provided the original work is properly cited.

Phenomena-based models can be used in a predictive manner, but statistical modelling methods can also yield interesting findings and can serve as a tool for analysing the effects of different variables on the overall phenomenon. In addition, the generation of theoretical models can sometimes be limited due to the unideality of the studied system. Statistical modelling, in this case multiplelinear regression (MLR), was used to describe the effects of temperature and acid concentration on the dissolution of magnetite, $\mathrm{Fe}_{3} \mathrm{O}_{4}$ with oxalic acid. Whereas a linear model with an interaction term was sufficient in describing the dissolution of synthetic $\mathrm{Fe}_{3} \mathrm{O}_{4}$, a more complex full quadratic model had to be used to describe the dissolution of industrial $\mathrm{Fe}_{3} \mathrm{O}_{4}$ in the same conditions.

\section{Introduction}

Both phenomena based thermodynamic and kinetic models could be utilised in the study of iron oxide dissolution. Sometimes the acquisition of data can, however, be very laborious and complex characteristics of the dissolution phenomenon may be difficult to account for through theory. Experimental modelling methods can provide an additional tool for understanding the behaviour of the system, for example the effects of different variables and the interaction of those variables to account for dissolution. Whereas kinetic studies of dissolution are common amongst metallurgist and soil scientists, equilibrium studies determining solubility are less published. Solubility, however, has key significance in any dissolution system because the difference between the equilibrium concentration and the concentration of the solute in the liquid phase determine the driving force for dissolution. Empirical modelling could also be found useful in describing solubility, as widely accepted theoretical models, for example, the Debye-Hückel law, do not apply in concentrated solutions.

Statistical modelling methods have been utilised to describe the kinetics of dissolution of iron from kaolin by chemical leaching and bioleaching [1]. In addition, nonlinear regression modelling has been employed in estimating the effects of different parameters, namely, sulphuric acid concentration, sucrose concentration, and temperature, on the acidic dissolution of manganiferous ores [2].

The dissolution of other components besides iron has also been described using statistical methods. The use of statistical methods in research of pharmaceuticals has been summarised elsewhere [3]. In particular principal component analysis (PCA) has been popular in analysing the dissolution profiles of different pharmaceuticals $[4,5]$. The solubility of calcium oxalate monohydrate has been statistically described as a function of temperature, calcium ion, magnesium ion, oxalic, and nitric acid concentrations of the solution [6]. An adequate correlation $\left(R^{2}=0.90\right)$ was achieved with a model comprising a linear and an interaction terms.

Although less used in the field of dissolution of magnetite, $\mathrm{Fe}_{3} \mathrm{O}_{4}$, statistical modelling methods have been successfully employed on other unit operations in ore beneficiation. Partial least squares (PLS) regression has been used to describe the dewatering process of $\mathrm{Fe}_{3} \mathrm{O}_{4}$ at $\mathrm{LKAB}$, Sweden [7]. Regression analysis, in turn, has been employed to study the performance of a horizontal belt filter [8]. Several techniques of experimental design were included in the study to determine the significance of operating parameters 
on the capacity, cake moisture content, and cake purity. In general, both linear and nonlinear models performed well in describing the response of the filtration process. The pelletising process of iron ore has been described with a quadratic model where the median pellet diameter was expressed as a function of the moisture percent of the material, the inclination angle of the pelletiser disc, and the pelletising time [9]. These studies mostly represent optimization cases but do go to show that different systems can be modelled with statistical techniques.

To the best knowledge of the authors, little attention has been paid on equilibrium studies of acidic dissolution of $\mathrm{Fe}_{3} \mathrm{O}_{4}$ whereas kinetic studies are more common [10-12]. The solubility of $\mathrm{Fe}_{3} \mathrm{O}_{4}$ has been investigated in $\mathrm{KOH}$ and in $\mathrm{HCl}$ solutions at elevated temperatures [13] but is essentially one of the very few published studies on the solubility of $\mathrm{Fe}_{3} \mathrm{O}_{4}$. In addition, the authors have not found publications reporting the applicability of experimental modelling methods in describing the acidic dissolution of $\mathrm{Fe}_{3} \mathrm{O}_{4}$ adding to the novelty of this specific approach. Whereas optimization and predictive models are common in experimental design and modelling, the applicability of experimental modelling could go far beyond those. Where discussion on the significance of different parameters, for example, the oxalate concentration [14-16], on the dissolution of iron oxides is undertaken, experimental models could provide additional insight to that discussion.

The aim of this study was to investigate the applicability of experimental models, based on empirical data, in describing the effects of temperature and acid concentration on the solubility of $\mathrm{Fe}_{3} \mathrm{O}_{4}$ in oxalic acid. Oxalic acid especially would be challenging for theoretical models because the dissolution mechanism consists of several steps, including adsorption, complex formation and even solid-state reduction [14-16]. Experimental models could, however, be used as tools to understand the behaviour of a dissolution system in respect to controllable parameters. Consequently, dissolution behaviour, to some extent, could be explained without physicochemical considerations.

\section{Methods}

2.1. Experimental. Two $\mathrm{Fe}_{3} \mathrm{O}_{4}$ powders were used for the dissolution experiments: a synthetic powder from Alfa Aesar and an industrial $\mathrm{Fe}_{3} \mathrm{O}_{4}$ concentrate. The purity of the synthetic sample, according to the supplier, was $97 \mathrm{wt} \%$ and, furthermore, the composition of the powder was verified with X-ray diffraction, using a Bruker D8 Advance diffractometer, and showed $\mathrm{Fe}_{3} \mathrm{O}_{4}$ as the only mineralogical phase. The industrial sample was also analysed by XRD and additionally with scanning electron microscopy coupled with energy dispersive X-ray spectrometer, using a JEOL JSM5800 scanning electron microscope, and indicated $68.77 \mathrm{wt} \%$ iron $(\mathrm{Fe})$ and $29.25 \mathrm{wt} \%$ oxygen $(\mathrm{O})$ with magnesium $(\mathrm{Mg})$, silicon $(\mathrm{Si})$, calcium $(\mathrm{Ca})$, aluminium $(\mathrm{Al})$, and titanium $(\mathrm{Ti})$ as impurities. Oxalic acid $\left(\mathrm{H}_{2} \mathrm{C}_{2} \mathrm{O}_{4} \cdot 2 \mathrm{H}_{2} \mathrm{O}\right)$ in concentrations of $0.08,0.33$, and $0.60 \mathrm{~mol} / \mathrm{L}$ was used to dissolve $\mathrm{Fe}_{3} \mathrm{O}_{4}$. The purity of the oxalic acid was $99 \%$. Values of initial $\mathrm{pH}$
TABLE 1: The $2^{3}$ full factorial design and the data used for modelling. Experiments 5, 6, and 7 represent the replicates of the center point of the full factorial, and experiment 12 is an additional center point for one of the corners of the experimental plan. The total number of experiments was 24 .

\begin{tabular}{lcccc}
\hline Number & $T,{ }^{\circ} \mathrm{C}$ & $\begin{array}{c}\text { Oxalic acid } \\
c, \text { mol/L }\end{array}$ & $\begin{array}{c}\text { Synthetic } \\
\mathcal{c}_{\mathrm{Fe}}, \mathrm{mg} / \mathrm{L}\end{array}$ & $\begin{array}{c}\text { Industrial } \\
\mathcal{c}_{\mathrm{Fe}}, \mathrm{mg} / \mathrm{L}\end{array}$ \\
\hline 1 & 15 & 0.08 & 1942 & 2576 \\
2 & 35 & 0.08 & 1996 & 2536 \\
3 & 50 & 0.08 & 3181 & 4021 \\
4 & 15 & 0.33 & 7523 & 4014 \\
5 & 35 & 0.33 & 11056 & 8114 \\
6 & 35 & 0.33 & 11704 & 7252 \\
7 & 35 & 0.33 & 11673 & 7825 \\
8 & 50 & 0.33 & 13522 & 8307 \\
9 & 15 & 0.60 & 18041 & 3193 \\
10 & 35 & 0.60 & 21001 & 10215 \\
11 & 50 & 0.60 & 21224 & 11289 \\
12 & 25 & 0.47 & 16051 & 7332 \\
\hline
\end{tabular}

were in the range of 0.79-1.34. Temperatures were 15, 35, and $50^{\circ} \mathrm{C}$. All solutions were prepared with ultrapure water. Because of lack of prior knowledge on such systems, the dissolution experiments here were conducted according to a $3^{2}$ full factorial design (Table 1) [17]. The experiments were conducted in a randomised order to decrease the effect of extraneous time-related factors [18].

A two-level design could have also been implemented but would have resulted in only five data points and would have limited the possibility of testing more complex models, for example, full quadratic models, because of limited degrees of freedom.

The experiments were conducted in a $1 \mathrm{~L}$ glass reactor equipped with a heating jacket, baffles, and a stirrer with a pitched blade turbine. Installation of the mixing device was done according to standard assembly [19]. The liquid was kept in constant temperature in the reactor and a blank sample was drawn, after which solids were introduced and mixing was commenced. Excess quantity of solids was used to obtain a thermodynamic equilibrium between the solid and the liquid phases. The total reaction time was $360 \mathrm{~min}$. The concentration of Fe in the liquid phase, after the reaction time, was measured with the ThermoElectron IRIS Intrepid II XLD inductively coupled plasma optical emission spectrometer (ICP-OES) and plotted against time. Although data were collected during the dissolution experiments, only the final Fe concentration was considered for modelling. Estimation of the total error of the sampling and analysis procedure, based on quantifiable error sources, indicated an experimental error of $2 \%$. The error consisted of uncertainty in the weighing of the primary sample, the volumetric dilution to obtain the secondary sample, and the inherent error of the analysis method. Additionally, the experimental error was estimated by repeating individual experimental points.

All the data on the dissolution experiments and a more extensive description of the experimental procedure and 
the materials (chemical composition and particle size distribution) used in this study have been presented elsewhere [20].

2.2. Modelling. Multiple Regression tools were employed in Matlab to generate the models describing the solubility of $\mathrm{Fe}$ as a function of the acid concentration and the temperature. The modelling was based on the equilibrium concentration of Fe (Table 1). Kinetic aspects, for example, pulp density or effects of different particle sizes, were not considered as variables here.

Firstly, linear models (1) with no interaction or quadratic terms were generated to study if fairly simple models would perform well in describing the dissolution. Models were evaluated based on the coefficient of determination, $R^{2}$, and the scatter plots of measured and modelled Fe concentrations:

$$
Y=\beta_{0}+\beta_{1} x_{1}+\beta_{2} x_{2}
$$

where linear modelling failed, interaction (see (2)) and quadratic terms (see (3) and (4)) were taken into account. Only the linear models with interaction terms or quadratic models best suited for describing the dissolution phenomena have been included in this paper but both were generated:

$$
\begin{aligned}
& Y=\beta_{0}+\beta_{1} x_{1}+\beta_{2} x_{2}+\beta_{3} x_{1} x_{2} \\
& Y=\beta_{0}+\beta_{1} x_{1}+\beta_{2} x_{2}+\beta_{3} x_{1}^{2}+\beta_{2} x_{2}^{2} \\
& Y=\beta_{0}+\beta_{1} x_{1}+\beta_{2} x_{2}+\beta_{3} x_{1} x_{2}+\beta_{4} x_{1}^{2}+\beta_{5} x_{2}^{2} .
\end{aligned}
$$

Equation (4) is from hereon called the full quadratic model. In general, not all the terms in (1)-(4) need to be taken into account if a good fit is obtained by excluding some of the terms.

A $P$ value of 0.05 or less was used to identify the statistical significance of each variable in the models containing only linear terms. A $P$ value of 0.05 , in practice, represents a $5 \%$ chance of an observed correlation being untrue, that is, not representative the studied phenomenon. The relative errors, in turn, were calculated by dividing the residuals (difference between the observed and modeled values) with the observed values for each data point.

\section{Results and Discussion}

The models for the three systems described in Section 2 are discussed in this section. Linear models, linear models with interaction terms, and quadratic models are introduced, where necessary, to demonstrate the applicability of different statistical models in describing the studied systems.

The maximum number of terms, when two variables are considered, would be six: (1) a constant, (2)-(3) linear terms of both variables, (4) an interaction term, and (5)-(6) quadratic terms of both variables. When applying statistical modelling it is, however, not self-evident that increasing parameters would result in a better model. Including additional terms can, but does not always, result in an increased $R^{2}$ value and in such cases the model could be explaining the systematic variance of the experimental data rather than the actual phenomena. In some cases, an additional term might not explain any of the variation left in the data after applying a purely linear model thus rendering no improvement in the model. The addition of parameters of any kind does not automatically mean a better model but can sometimes produce desired results.

3.1. Synthetic $\mathrm{Fe}_{3} \mathrm{O}_{4}$. The linear regression model, not including an interaction term, for the synthetic $\mathrm{Fe}_{3} \mathrm{O}_{4}$-oxalic acid system was generated using the whole data set for the system ((5), Figure 1(a)):

$$
c_{\mathrm{Fe}, \mathrm{eq}}=-3.5 \cdot 10^{3} \frac{\mathrm{mg}}{\mathrm{L}}+96.2 \frac{\mathrm{mg}}{\mathrm{L} \cdot{ }^{\circ} \mathrm{C}} \cdot T+3.4 \cdot 10^{4} \frac{\mathrm{mg}}{\mathrm{mol}} \cdot c_{\text {acid }},
$$

where $c_{\mathrm{Fe}, \text { eq }}$ is concentration of dissolved $\mathrm{Fe}$ at equilibrium, $\mathrm{mg} / \mathrm{L}, \mathrm{T}$ temperature, ${ }^{\circ} \mathrm{C}, c_{\text {acid }}$ concentration of the acid, $\mathrm{mol} / \mathrm{L}$.

The fit was good having an $R^{2}$ value of 0.983 . The $P$ values for the constant and for the two variables were $0.006,0.002$, and 0.000 , respectively, meaning that all the terms included in the model were significant.

The model seemed to estimate the solubility better with higher equilibrium concentrations, meaning that the difference between the observed and the predicted values was larger for low values of solubility and smaller for high values. The largest relative errors were observed with data points $1-4$, from 20 to $64 \%$. With the exception of data point 1 , the predicted solubility was higher than the observed one. Data points 5-12 had significantly smaller errors with a maximum error of $6.5 \%$ between the observed and predicted values.

Including the interaction term did not significantly improve the $R^{2}$ value (0.984) or the fit in general (Figure 1(b)), but the residuals for this model (6) were smaller than for the linear model. The difference here was that including the interaction term decreased the errors in the predicted values as compared to the observed ones at those smaller equilibrium concentration which were found challenging for (5). The errors in data points $1-4$ were now from 14 to $41 \%$. The errors in the other data points did not change significantly:

$$
\begin{aligned}
c_{\mathrm{Fe}, \mathrm{eq}}= & -2.4 \cdot 10^{3} \frac{\mathrm{mg}}{\mathrm{L}}+63.4 \frac{\mathrm{mg}}{\mathrm{L} \cdot{ }^{\circ} \mathrm{C}} \cdot T+3.1 \cdot 10^{4} \frac{\mathrm{mg}}{\mathrm{mol}} \cdot c_{\mathrm{acid}} \\
& +96.2 \frac{\mathrm{mg}}{{ }^{\circ} \mathrm{C} \cdot \mathrm{mol}} \cdot T \cdot c_{\text {acid }} .
\end{aligned}
$$

Both the linear model and the model including the interaction term exhibited very similar behaviour: a negative constant and an increased response with increasing variables. The regression coefficients for the variables were, in fact, very alike for the two models, which could be expected as including the interaction term only slightly affected the coefficient of determination, $R^{2}$.

3.2. Industrial $\mathrm{Fe}_{3} \mathrm{O}_{4}$. The linear model (see (7)) describing the industrial $\mathrm{Fe}_{3} \mathrm{O}_{4}$-oxalic acid system (Figure 2(a)) was not successful, as also indicated by $R^{2}$ of 0.746 . 


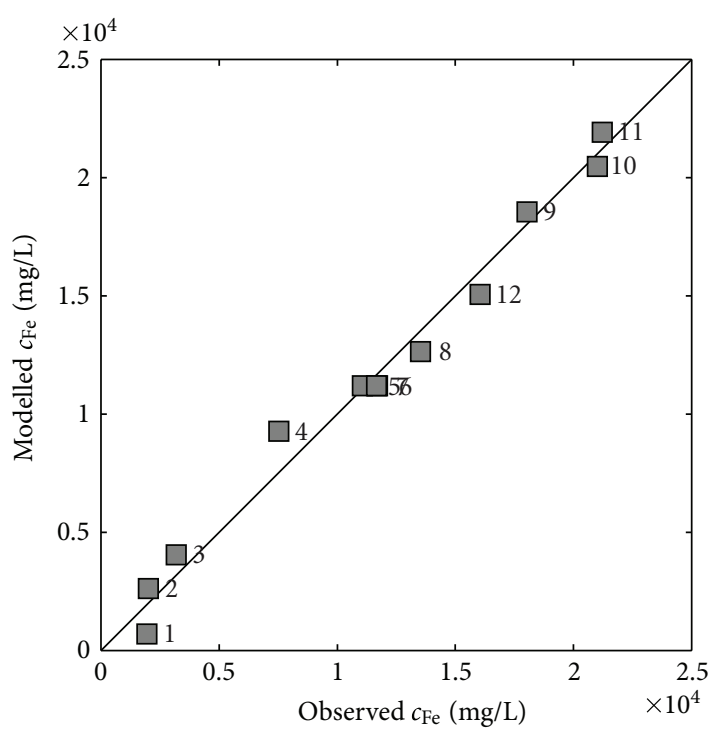

(a)

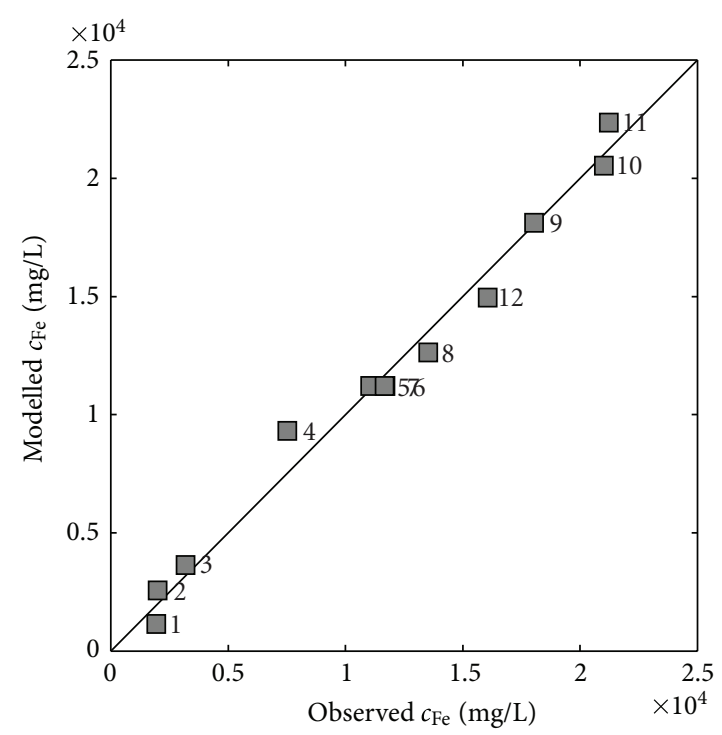

(b)

Figure 1: Synthetic $\mathrm{Fe}_{3} \mathrm{O}_{4}$-oxalic acid. Scatter plot of the measured Fe concentration against the modeled one (a) for the purely linear model and (b) for the linear model with the interaction term. 0.004:

Here, the $P$ values for the terms were $0.385,0.007$, and

$$
c_{\mathrm{Fe}, \mathrm{eq}}=-1.5 \cdot 10^{3} \frac{\mathrm{mg}}{\mathrm{L}}+133.1 \frac{\mathrm{mg}}{\mathrm{L} \cdot{ }^{\circ} \mathrm{C}} \cdot T+1.0 \cdot 10^{4} \frac{\mathrm{mg}}{\mathrm{mol}} \cdot c_{\text {acid }} .
$$

The relative errors varied on a wide scale, and an individual observation of a relative error above $100 \%$ made. Such a model would most likely not be suitable for any purpose.

A nonlinear model performed better but was still left with a poor coefficient of determination and a poor fit of the model with the data $\left(R^{2}=0.860\right.$, Figure $\left.2(\mathrm{~b})\right)$ :

$$
\begin{aligned}
c_{\mathrm{Fe}, \text { eq }}= & 2.7 \cdot 10^{3} \frac{\mathrm{mg}}{\mathrm{L}}+7.6 \frac{\mathrm{mg}}{\mathrm{L} \cdot{ }^{\circ} \mathrm{C}} \cdot T-2.0 \cdot 10^{3} \frac{\mathrm{mg}}{\mathrm{mol}} \cdot c_{\mathrm{acid}} \\
& +367.9 \frac{\mathrm{mg}}{{ }^{\circ} \mathrm{C} \cdot \mathrm{mol}} \cdot \mathrm{T} \cdot c_{\mathrm{acid}} .
\end{aligned}
$$

With the investigation of (8), one could immediately see that the model was completely different to all the previous ones. The constant was not found negative but the coefficient for acid concentration was, which led to suspect if this model would indeed describe the actual phenomenon at all. Here, the relative errors did, however, decrease. Although for most data points the errors were below $15 \%$, individual data points exhibited errors of roughly $50 \%$.

As the introduction of the interaction term did not produce the desired improvement in the modelling, the incorporation of quadratic terms was investigated. The interaction term was not included here. The results were not significantly improved, as the $R^{2}$ value was left unchanged (0.860).

Finally, a full quadratic model was generated to improve the fit. A significant improvement was observed in the $R^{2}$ value (0.957) as well as in the fit of the model with the experimental data $((9)$, Figure $2(\mathrm{c}))$ :

$$
\begin{aligned}
c_{\mathrm{Fe}, \mathrm{eq}}= & -1.7 \cdot 10^{3} \frac{\mathrm{mg}}{\mathrm{L}}+230.2 \frac{\mathrm{mg}}{\mathrm{L} \cdot{ }^{\circ} \mathrm{C}} \cdot \mathrm{T} \\
& +1.0 \cdot 10^{4} \frac{\mathrm{mg}}{\mathrm{mol}} \cdot c_{\mathrm{acid}}+377.4 \frac{\mathrm{mg}}{{ }^{\circ} \mathrm{C} \cdot \mathrm{mol}} \cdot T \cdot c_{\mathrm{acid}} \\
& -3.5 \frac{\mathrm{mg}}{\mathrm{L} \cdot{ }^{\circ} \mathrm{C}^{2}} \cdot T^{2}-1.8 \cdot 10^{4} \frac{\mathrm{mg}}{\mathrm{mol}} \cdot c_{\mathrm{acid}}^{2} .
\end{aligned}
$$

Here, the relative errors for data points $1-3$ were the highest and varied from 19 to $49 \%$. Otherwise, relative errors below $10 \%$ were observed. By excluding the linear terms or even the first quadratic term, $R^{2}$ of 0.904 and 0.887 , respectively, could have been achieved and might be considered adequate for rough estimation in an industrial environment. Here, the objective was, however, to describe as accurately as possible the equilibrium concentration of $\mathrm{Fe}$ in the mother liqueur in order to make comparison between the two solid powders, and the model was thus rejected.

The centre point of the experimental plan was repeated three times, where all repetitions for the synthetic $\mathrm{Fe}_{3} \mathrm{O}_{4}$ were found to fit within $4 \%$ of experimental error. The corresponding experimental error was roughly $6 \%$ for the industrial $\mathrm{Fe}_{3} \mathrm{O}_{4}$. The larger experimental error could have been a result of the inhomogeneous nature of the industrial sample. The particle size distribution and impurities in the sample could have resulted in varying results in the repeated experiments.

3.3. Comparison of the Two Powders. Essentially, two methods of comparison can be used for regression models: (1) comparison based on regression coefficients and (2) comparison based on main effects of the models. In this case, 


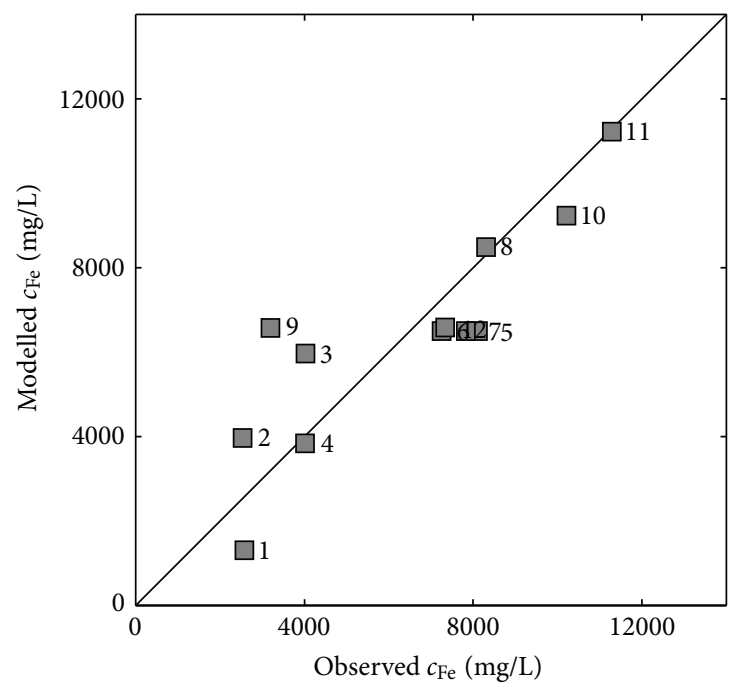

(a)

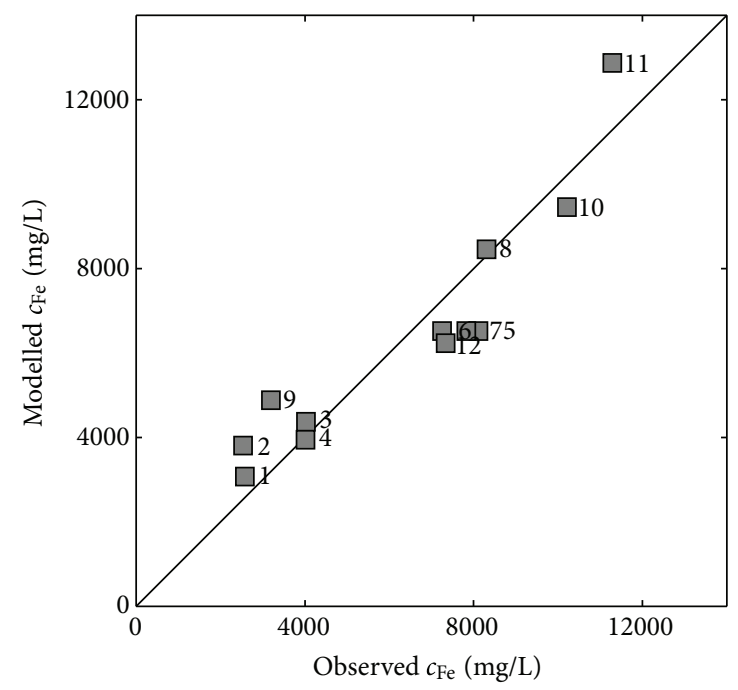

(b)

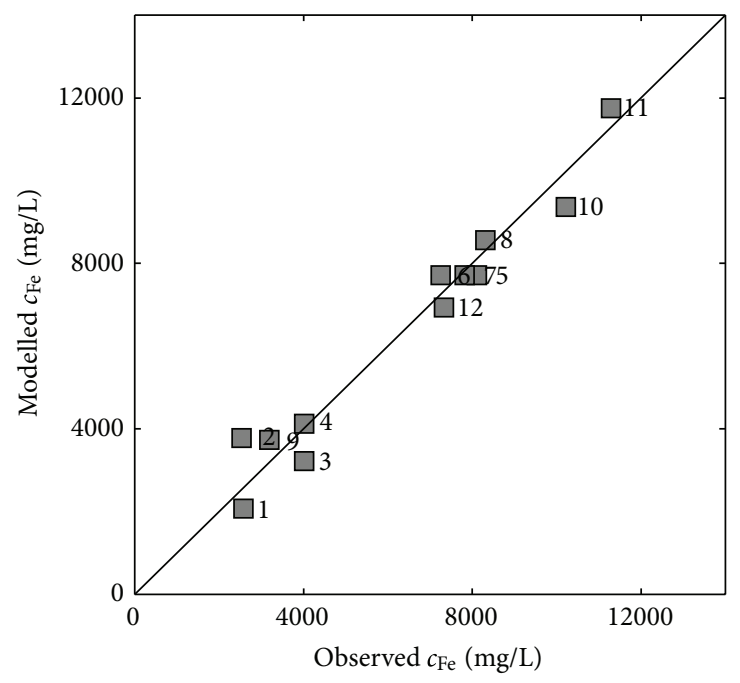

(c)

FIGURE 2: Industrial $\mathrm{Fe}_{3} \mathrm{O}_{4}$-oxalic acid. Scatter plot of the measured Fe concentration against the modeled one (a) for the purely linear model, (b) for the linear model including an interaction term, and (c) for the full quadratic model.

mere regression coefficients could not be directly used for the comparison of the different models, because the data were not scaled before applying the numerical methods, and the coefficients were, therefore, affected by the variable ranges. Although scaling the data would have made it possible to evaluate the significance of each term from the regression coefficients alone, the models would not have been generated with real values of the variables but with scaled values which could make the application of the models more laborious for industrial purposes. Thus, no real added value would have been achieved by scaling the data. Consequently, here the comparison of the different models was done based on the analysis of the main effects.

Main effects of a statistical model are more difficult to compare when interaction terms are taken into the model. With linear models, every variable is represented by only one model term making it easier to estimate the effect of the variable on the response. Interaction terms, as in this case, include several of the variables under investigation which means that when evaluating the magnitude of the effect of a single variable, the effect coming from the interaction term should also be considered. Because of these characteristics of statistical models, it was best to evaluate the effect of single variables using purely linear models where interaction terms did not yield interference in the interpretation.

Main effects (Table 2) were calculated for both of the studied variables in the selected variable space. The main effects, in this case, were calculated simply by multiplying the appropriate regression coefficient with the change $(\Delta T$, $\left.\Delta c_{\text {acid }}\right)$ in the appropriate variable.

In the dissolution of industrial $\mathrm{Fe}_{3} \mathrm{O}_{4}$, the effect of the acid concentration in the studied variable space was found similar to the dissolution of synthetic $\mathrm{Fe}_{3} \mathrm{O}_{4}$ : increase in the acid concentration increased the concentration of dissolved 
TABLE 2: $R^{2}$ values and main effects of the variables for both oxalic acid- $\mathrm{Fe}_{3} \mathrm{O}_{4}$ systems with purely linear models.

\begin{tabular}{lcccc}
\hline Equation & Magnetite & $R^{2},-$ & $T, \mathrm{mg} / \mathrm{L}$ & $c_{\text {acid }}, \mathrm{mg} / \mathrm{L}$ \\
\hline$(5)$ & Synthetic & 0.983 & 3367.0 & 17680.0 \\
$(7)$ & Industrial & 0.746 & 4658.5 & 5200.0 \\
\hline
\end{tabular}

iron. The effect of the acid concentration in increasing solubility was not as significant as it was in dissolving synthetic $\mathrm{Fe}_{3} \mathrm{O}_{4}$. The smaller effect of the acid concentration could be explained by the dissolution of impurities from the industrial material: impurities with higher solubility than Fe oxide consumed the acid. Consequently, the apparent increase in acid concentration was not completely directed at the dissolution of iron resulting in a smaller total effect. The dissolution of the impurities has also been discussed elsewhere [20].

\section{Conclusions}

The applicability of MLR to describe the effects of temperature and acid concentration on the solubility of $\mathrm{Fe}_{3} \mathrm{O}_{4}$ in oxalic acid was studied by creating linear and nonlinear regression models based on the dissolution data.

The effects of temperature and acid concentration on the dissolution of synthetic $\mathrm{Fe}_{3} \mathrm{O}_{4}$ in oxalic acid, specifically on the equilibrium concentration of iron in the liquid phase, could be explained by linear models well. The concentration of oxalic acid was found highly significant in the dissolution of $\mathrm{Fe}_{3} \mathrm{O}_{4}$ and can be explained by the increase of available ligands enabling the dissolution. Consequently, even the statistical models do, to a certain extent, yield relevant tools to identify the significance of different factors. In developing a new dissolution process, these tools could be used to determine the most desirable direction for further experimentation: can we increase recovery most effectively by increasing the temperature or by introducing more chelating agents into the system?

To describe the dissolution of an industrial powder in the same conditions required the application of nonlinear models including interaction and quadratic terms. The dissolution of impurities from the industrial $\mathrm{Fe}_{3} \mathrm{O}_{4}$ could explain the need for more complex models as the cooccurring dissolution of the impurities might interfere with the dissolution of the $\mathrm{Fe}_{3} \mathrm{O}_{4}$. The same conclusion might apply also to the observed difference with the two powders regarding the effect of temperature: in the dissolution of the synthetic powder, increasing the acid concentration played a much greater role than increasing the temperature, whereas the effect was roughly the same for increasing either of the variables.

Extrapolation should never be attempted based on purely empirical models. Empirical, and in this case statistical, models only apply in the variable space in which the models were generated. As seen here, the regression models performed poorly in explaining data collected at low temperature and high acid concentration.

\section{Acknowledgments}

This study was supported by the Graduate School in Chemical Engineering and by Outotec (Filters) Oy.

\section{References}

[1] V. Arslan and O. Bayat, "Removal of Fe from kaolin by chemical leaching and bioleaching," Clays \& Clay Minerals, vol. 57, no. 6, pp. 787-794, 2009.

[2] F. Beolchini, M. Petrangeli Papini, L. Toro, M. Trifoni, and F. Vegliò, "Acid leaching of manganiferous ores by sucrose: kinetic modelling and related statistical analysis," Minerals Engineering, vol. 14, no. 2, pp. 175-184, 2001.

[3] T. O’Hara, A. Dunne, J. Butler, and J. Devane, "A review of methods used to compare dissolution profile data," Pharmaceutical Science and Technology Today, vol. 1, no. 5, pp. 214-223, 1998.

[4] E. Adams, R. De Maesschalck, B. De Spiegeleer, Y. Vander Heyden, J. Smeyers-Verbeke, and D. L. Massart, "Evaluation of dissolution profiles using principal component analysis," International Journal of Pharmaceutics, vol. 212, no. 1, pp. 41-53, 2001.

[5] R. M. Maggio, P. M. Castellano, and T. S. Kaufman, "PCA$\mathrm{CR}$ analysis of dissolution profiles. A chemometric approach to probe the polymorphic form of the active pharmaceutical ingredient in a drug product," International Journal of Pharmaceutics, vol. 378, no. 1-2, pp. 187-193, 2009.

[6] R. Salmimies, M. Louhi-Kultanen, B. Ekberg, A. Häkkinen, J. Kallas, and M. Huhtanen, "Fouling of filter media: solubility of oxalate solutions," in Proceedings of the 10th World Filtration Congress, pp. 14-18, Leipzig, Germany, April 2008.

[7] B. Herath, C. Albano, A. Anttila, and B. Flykt, "Empirical modelling of a dewatering process using multivariate data analysis," Filtration and Separation, vol. 29, no. 1, pp. 44-57, 1992.

[8] M. Huhtanen, A. Häkkinen, B. Ekberg, and J. Kallas, "Experimental study of the influence of process variables on the performance of a horizontal belt filter," Filtration, vol. 11, no. 2, pp. 120-125, 2011.

[9] J. S. Thella and R. Venugopal, "Modeling of iron ore pelletization using $3^{* *(\mathrm{~K}-\mathrm{P})}$ factorial design of experiments and polynomial surface regression methodology," Powder Technology, vol. 211, no. 1, pp. 54-59, 2011.

[10] P. S. Sidhu, R. J. Gilkes, R. M. Cornell, A. M. Posner, and J. P. Quirk, "Dissolution of iron oxides and oxyhydroxides in hydrochloric and perchloric acids," Clays \& Clay Minerals, vol. 29, no. 4, pp. 269-276, 1981.

[11] V. I. E. Bruyére and M. A. Blesa, "Acidic and reductive dissolution of magnetite in aqueous sulfuric acid. Site-binding model and experimental results," Journal of Electroanalytical Chemistry, vol. 182, no. 1, pp. 141-156, 1985.

[12] M. A. Blesa, H. A. Marinovich, E. C. Baumgartner, and A. J. G. Maroto, "Mechanism of dissolution of magnetite by oxalic acidferrous ion solutions," Inorganic Chemistry, vol. 26, no. 22, pp. 3713-3717, 1987.

[13] F. H. Sweeton and C. F. Baes, "The solubility of magnetite and hydrolysis of ferrous ion in aqueous solutions at elevated temperatures," The Journal of Chemical Thermodynamics, vol. 2, no. 4, pp. 479-500, 1970. 
[14] D. Panias, M. Taxiarchou, I. Paspaliaris, and A. Kontopoulos, "Mechanisms of dissolution of iron oxides in aqueous oxalic acid solutions," Hydrometallurgy, vol. 42, no. 2, pp. 257-265, 1996.

[15] M. Taxiarchou, D. Panias, I. Douni, I. Paspaliaris, and A. Kontopoulos, "Dissolution of hematite in acidic oxalate solutions," Hydrometallurgy, vol. 44, no. 3, pp. 287-299, 1997.

[16] S. O. Lee, T. Tran, Y. Y. Park, S. J. Kim, and M. J. Kim, "Study on the kinetics of iron oxide leaching by oxalic acid," International Journal of Mineral Processing, vol. 80, no. 2-4, pp. 144-152, 2006.

[17] G. E. P. Box, W. G. Hunter, and J. S. Hunter, Statistics for Experiments, John Wiley \& Sons, Hoboken, NJ, USA, 1987.

[18] D. Montgomery, Design and Analysis of Experiments, John Wiley \& Sons, Toronto, Canada, 1997.

[19] G. Tatterson, Scaleup and Design of Industrial Mixing Processes, McGraw-Hill, New York, NY, USA, 1994.

[20] R. Salmimies, M. Mannila, J. Kallas, and A. Häkkinen, "Acidic dissolution of magnetite: experimental study on the effects of acid concentration and temperature," Clays \& Clay Minerals, vol. 59, no. 2, pp. 136-146, 2011. 

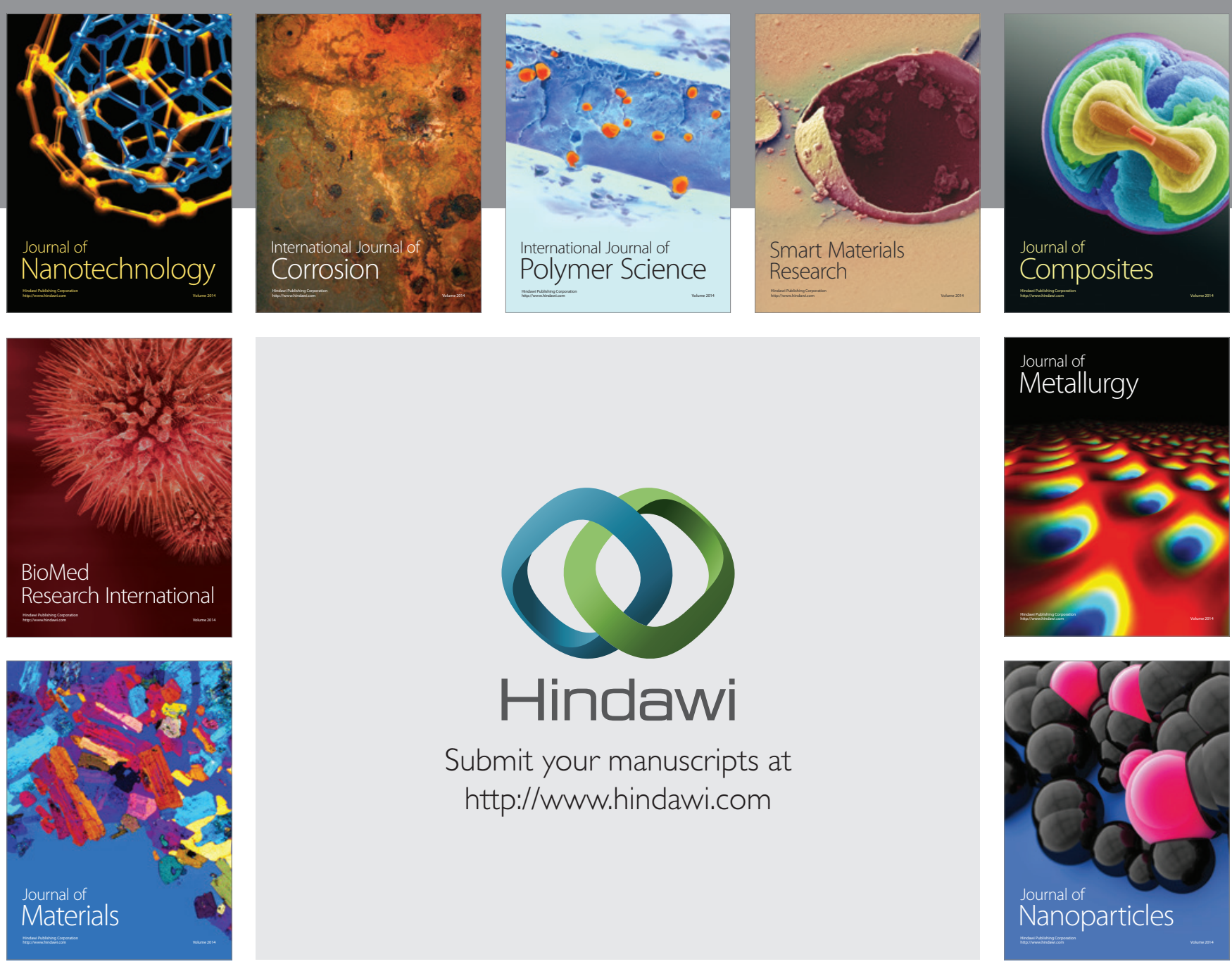

Submit your manuscripts at http://www.hindawi.com
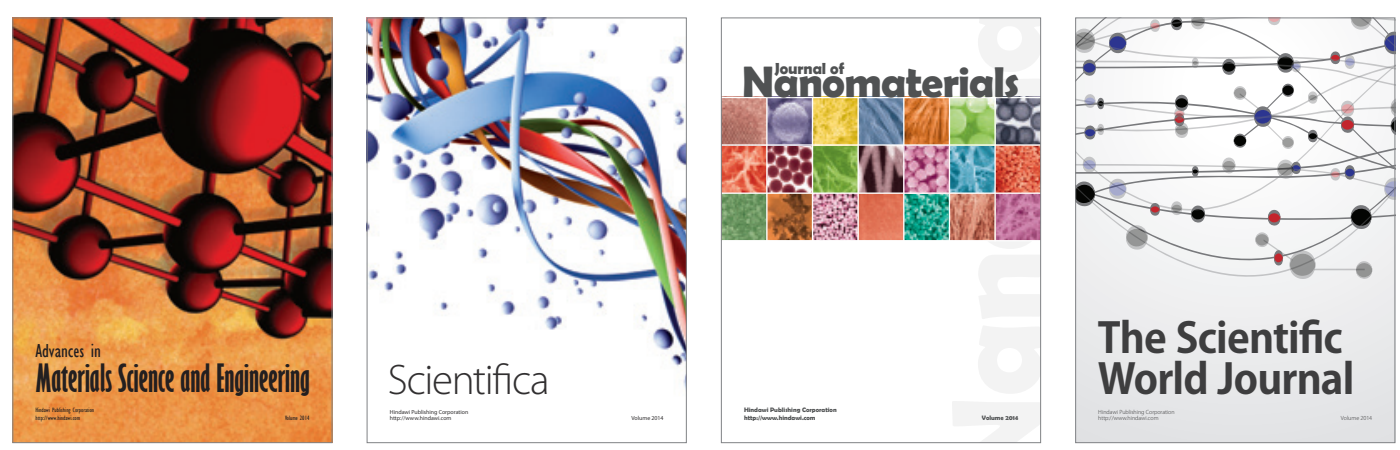

\section{The Scientific World Journal}
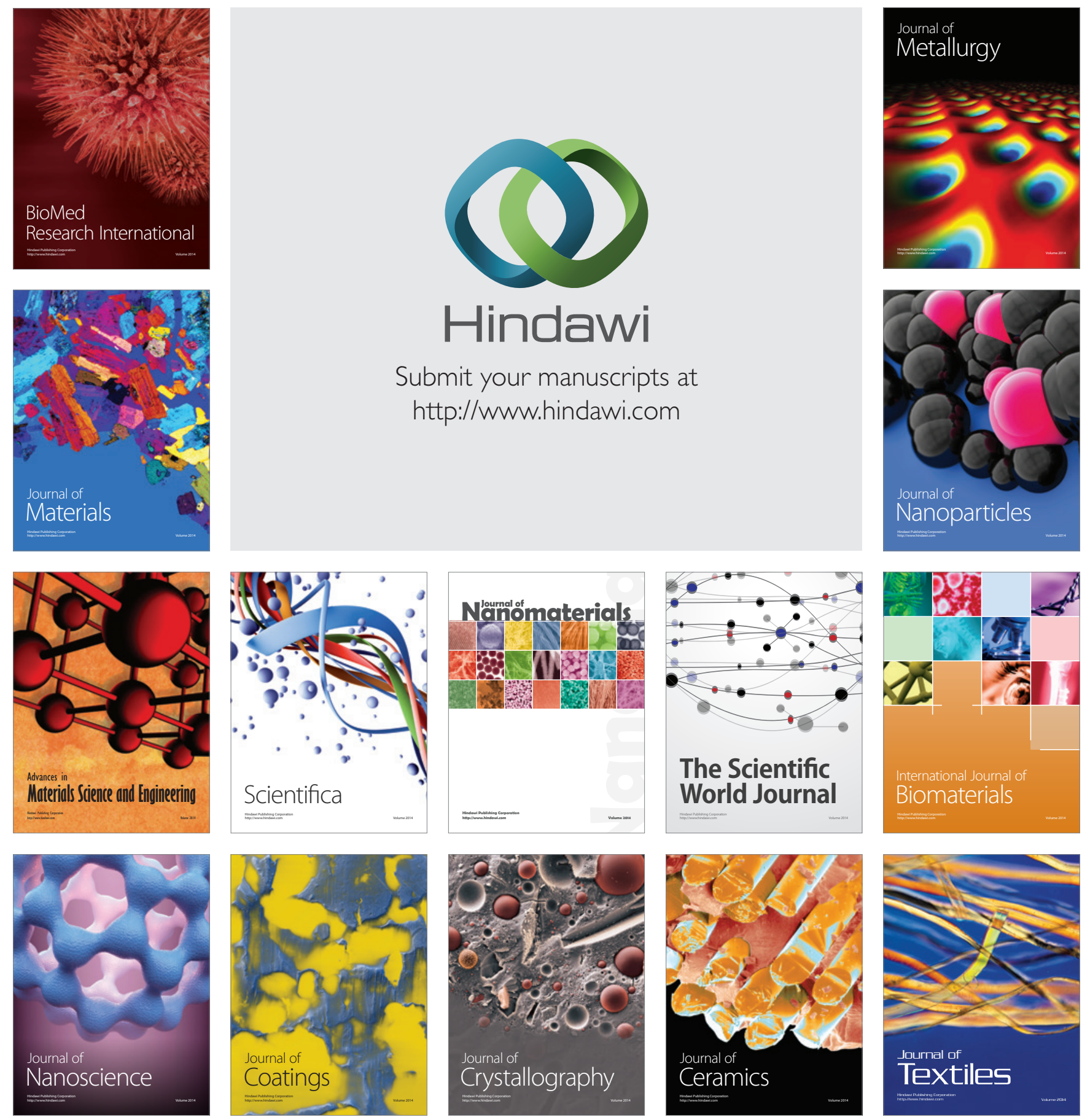